\title{
Relationships Between Rational Beliefs and Anxiety ${ }^{1}$
}

\author{
David P. Himle, ${ }^{2}$ Bruce A. Thyer, and James D. Papsdorf \\ The University of Michigan
}

The relationships between rationality, as measured by the recently developed Rational Behavior Inventory (RBI), and several commonly used measures of anxiety are examined in both a general student sample $(N=$ 144) and a clinically tested anxious sample $(N=34)$. Although differing aspects of rationality were related to anxiety for the two groups, consistent negative correlations were found between specific irrational beliefs and measures of test, state, and trait anxiety. The observed relationships of decreased rationality associated with increased levels of anxiety lend support to the theoretical basis of cognitive restructuring forms of therapy, and to the concurrent validity of the RBI.

The recent trend toward incorporating cognitively based procedures into the general practice of behavior therapy (Mahoney, 1977; Meichenbaum, 1977) is based upon the theory that the rationality of an individual's personal belief systems and internal self-statements is largely responsible for his emotional and behavioral responses. Numerous clinical outcome studies attest to the efficacy of such cognitively based therapies (Ellis \& Grieger, 1977), and several correlational studies have found associations between the degree of irrationality of a subject's beliefs and the degree of psychopathology. For example, using the Irrational Beliefs Test (IBT) developed by Jones (1969) and several measures of emotional arousal, Goldfried and Sobocinski (1975) found significant correlations between specific aspects of irrational beliefs and measures of state, trait, and achievement anxiety.

\footnotetext{
${ }^{1}$ Portions of this paper have been presented at the Third National Conference on Rational Emotive Therapy, New York, May 6-8, 1980. An extended version of this report is available upon request.

${ }^{2}$ Address all correspondence to David P. Himle, School of Social Work, 1065 Frieze Building, The University of Michigan, Ann Arbor, Michigan 48109.
} 
Forman and Forman (1979) also found that the total IBT score and five of its subscales were significantly associated with psychological needs.

Utilizing a different measure of the rationality of a subject's personal belief systems, the recently developed Rational Behavior Inventory (RBI), Whiteman and Shorkey (1978) found RBI scores to be significantly correlated with measures of anomia, authoritarianism, dogmatism, and selfesteem, as well as with self-actualization (Shorkey \& Reyes, 1978). To this date, research examining the relationships between the RBI and other personality and behavioral measures has been lacking. Therefore, the purpose of the present investigation was to replicate the research of Goldfried and Sobocinski (1975) utilizing an alternative measure of rational beliefs, the RBI. This would address the theoretical premise of cognitive therapies and add to the data on the concurrent validity of the RBI.

\section{METHOD}

\section{Subjects}

Two separate correlational studies were conducted. The first utilized a heterogeneous group of undergraduate psychology students $(N=144)$, who participated in a variety of psychological experiments and completed the measures in return for partial research credit. The general student (GS) group consisted of 69 males and 75 females. The clinially test-anxious group (TA) consisted of all participants who enrolled in the university's Test Anxiety Program during the previous year $(N=34)$. All subjects in this latter group reported a history of test anxiety extending back for several years. Subjects in this group paid a $\$ 30$ fee to enroll in the eight week treatment program and were recruited through advertisements placed in local newspapers and posters displayed throughout the campus. The TA group was composed of 14 males and 20 females.

\section{Measures}

The RBI yields on overall index of rationality, with higher scores indicating greater rationality, which is composed of 11 separate factor scores derived using factor-analytic procedures, each one relating to a key component of rationality (Shorkey \& Whiteman, 1977). These 11 separate factors are (1) catastrophizing, (2) guilt, (3) perfectionism, (4) need for approval, (5) caring and helping, (6) blame and punishment, (7) inertia and avoidance, (8) independence, (9) self-downing, (10) projected misfortune, 
and (11) control of emotions. A total of three anxiety measures were administered to all subjects. The State-Trait Anxiety Inventory (Spielberger, Gorsuch, \& Lushene, 1970) consists of two separate Likert-type questionnaires, each with a range of scores from 20 to 80 , which respectively measure transient anxiety induced by temporary environmental stressors (STAI-S), and more enduring anxiousness that is presumably based upon personality traits less subject to change by external events (STAIT). Higher scores indicate greater amounts of anxiousness. The Test Anxiety Inventory (TAI) is a 20-item Likert-type questionnaire that also has a range of scores from 20 to 80 , with higher scores indicating greater amounts of test anxiety (Spielberger, 1980). This latter measure was included to observe the relationship between rationality and a highly specific form of state (test-taking) anxiety, as opposed to the nonspecific indices of the STAI.

\section{Procedure}

All subjects in the GS group completed the inventories as part of a battery of psychological tests administered in conjunction with a series of studies on the effects of test anxiety level, subjects sex, and distraction on cognitive performance and physiological arousal. Subjects constituting the TA sample similarly completed the inventories as a part of a battery of psychological tests that were a portion of the pretreatment assessment procedure of the test anxiety program.

\section{RESULTS}

Table I shows the Pearson product-moment correlation coefficients between the total RBI score and the individual factors, and the TAI, STAI-T, and STAI-S for the two groups. The observed correlations are largely negative, indicating that as RBI scores are observed to increase (in the direction of greater rationality), scores on the anxiety measures decrease.

\section{DISCUSSION}

The data indicate that the total RBI score and several of the RBI subfactors are significantly negatively correlated with the anxiety scales used in this study, replicating the observations of Goldfried and Sobocinski (1975), who employed a different measure of rationality, the Irrational 


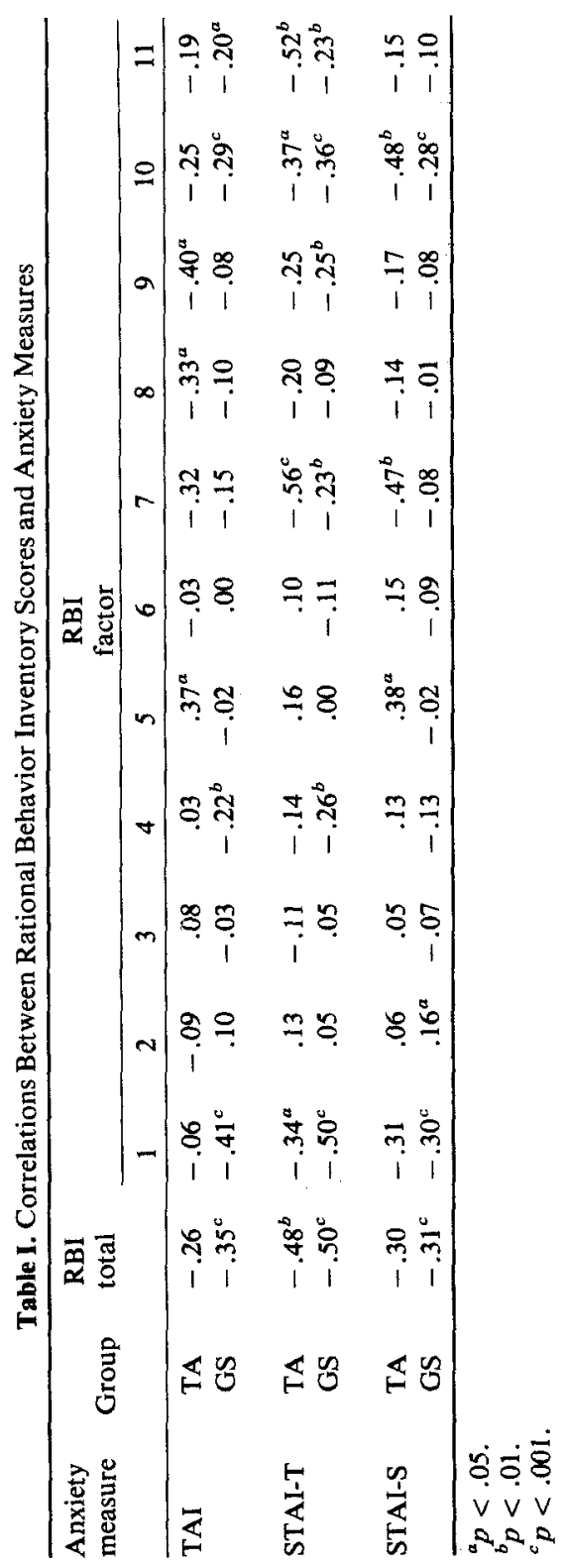


Beliefs Test. The finding lends general support to the theoretical premise that irrational cognitions are associated with various emotional and behavioral disorders. Trait anxiety scores are strongly associated with the RBI total scores in both groups. This would be expected since enduring patterns of irrational thinking would seem to be associated with enduring levels of anxiety.

There are some important differences in the correlational patterns observed between the two groups of subjects. Whereas in the GS group the total RBI score and factors $1,4,10$, and 11 correlate significantly with at least two of the anxiety scales, in the TA group only factors 5, 7, and 10 correlate with at least two of the anxiety scales. Apart from differences caused by the fewer degrees of freedom found with the smaller TA group, the data suggest that the RBI is associated with particular aspects of anxiety dependent upon the type of subject sample under investigation. Future research with the RBI should attempt to examine the patterns of irrationality found in clinically anxious patients, in a variety of settings.

\section{REFERENCES}

Ellis, A., \& Greiger, R. Handbook of rational emotive therapy. New York: Julian Press, 1977.

Forman, B., \& Forman, S. Irrational beliefs and psychological needs. Journal of Personality Assessment, 1979, 43, 633-637.

Goldfried, M., \& Sobocinski, D. Effects of irrational beliefs on emotional arousal. Journal of Consulting and Clinical Psychology, 1975, 43, 504-510.

Jones, R. The irrational beliefs test. Wichita, Kansas: Test Systems Incorporated, 1969.

Mahoney, M. Reflections on the cognitive-learning trend in psychotherapy. American Psychologist, 1977, 32, 5-12.

Meichenbaum, D. Cognitive-behavior modification. New York: Plenum, 1977.

Shorkey, C., \& Reyes, E. Relationship between self-actualization and rational thinking. Psychological Reports, 1978, 42, 842.

Shorkey, C. T., \& Whiteman, V. L. Development of the rational behavior inventory: initial validity and reliability. Educational and Psychological Measurement, 1977, 37, 527-534.

Spielberger, C. The Test Anxiety Inventory (TAI). Palo Alto, California: Consulting Psychologists Press, 1980.

Spielberger, C., Gorsuch, R., \& Lushene, R. Manual for the State-Trait Anxiety Inventory. Palo Alto, California: Consulting Psychologists Press, 1970.

Whiteman, V., \& Shorkey, C. Validation testing of the rational behavior inventory. Educational and Psychological Measurement, 1978, 38, 1143-1149. 